\title{
Transcriptional activity of the symbiotic plasmid of Rhizobium etli is affected by different environmental conditions
}

\author{
Lourdes Girard, ${ }^{1}$ Brenda Valderrama, ${ }^{2}$ Rafael Palacios, ${ }^{1}$ David Romero ${ }^{1}$ \\ and Guillermo Dávila'
}

Author for correspondence: Lourdes Girard. Tel: +52 73 175867. Fax : +52 73175581.

e-mail: girard@cifn.unam.mx

Departamentos de

Genética Molecular' and

Ecología Molecular².

Centro de Investigación sobre Fijación de

Nitrógeno, Universidad Nacional Autónoma de México, Ap. Postal 565-A, Cuernavaca, Morelos, Mexico

\begin{abstract}
Global patterns of transcriptional activity of the symbiotic plasmid (pSym) of Rhizobium etli were studied under a variety of environmental conditions, including some relevant to the symbiotic process. ${ }^{32}$-labelled single-stranded complementary DNAs synthesized from total RNA were used as hybridization probes against an ordered collection of cosmid clones that covered the whole pSym. Our results showed that, under aerobic conditions, discrete regions of the pSym are differentially transcribed depending on the carbon and nitrogen sources employed. In general, poor carbon or nitrogen sources allowed greater expression than rich ones. Time-course experiments with the nod gene inducer genistein led us to the identification of new regions responsive to this flavonoid. Widespread transcription was observed during microaerobiosis, but not under aerobic conditions, indicating that oxygen concentration is a major effector of transcriptional activity in the pSym. This response was reduced, but not suppressed, in a nifA mutant, indicating the location of regions whose transcription may depend on other oxygen-sensitive regulators. During symbiosis, almost the entire pSym was actively transcribed and the transcription pattern was similar to that observed during microaerobiosis. The experimental approach described allowed the identification and localization of specific regions in the pSym whose expression depends on defined environmental stimuli.
\end{abstract}

Keywords: Rbizobium etli, symbiotic plasmid, pSym, nodulation, transcription

\section{INTRODUCTION}

In Rbizobium species, more than fifty different genes that participate in nodulation and nitrogen fixation have been identified (Fischer, 1994; Schultze et al., 1994; Van Rhijn \& Vanderleyden, 1995). Current research is mostly devoted to clarifying the role of specific genes in definite steps of the Rbizobium-legume interaction (Carlson $e t$ al., 1994; Schultze et al., 1994). In several Rhizobium species, most of these genes are clustered in a sector of a single large plasmid, the so-called symbiotic plasmid or pSym. Complete physical maps of the pSyms of some Rbizobium species have been published (Girard $e t$ al., 1991 ; Perret $e t$ al., 1991); genes involved in the symbiotic process cover

Abbreviation: ${ }^{32} \mathrm{P}-\mathrm{sscDNA}$, ${ }^{32} \mathrm{P}$-labelled single-stranded complementary DNA. a relatively small zone of these megaplasmids. It is commonly assumed that some of the remaining genetic information is required for stable maintenance of the plasmid, or that it participates in other, as yet undescribed, processes.

The identification of many symbiotic genes has been achieved mainly through loss of function approaches, such as random transposon mutagenesis and/or gene fusion techniques. Cloning and sequencing of interesting regions and their surroundings has been useful, due to the observed clustering of genes involved in the symbiotic process (Sanjuan et al., 1993). However, application of these approaches to the identification of regions responding to different environmental stimuli usually requires new mutant hunts or extensive sequencing efforts. Moreover, these strategies usually do not detect genes with a leaky phenotype when mutated. This situation may arise 
either when active reiterations (a common situation in Rhizobium species) or alternative pathways occur. These strategies may also fail to detect genes with an ancillary, albeit important, role in the symbiotic interaction. These limitations probably result in an underestimation of the actual number of genes participating in bacteria-plant interactions.

A global approach for the detection of transcriptional activity under specific conditions offers an alternative to circumvent the above problems. This strategy relies on the quantitative detection of regions undergoing active transcription under diverse experimental conditions. Application of this strategy to sectors of the genome where a comprehensive map is available allows a positional evaluation of gene activity in response to the stimulus to be tested (Chuang et al., 1993). A similar approach was recently employed on the pSym of Rbizobium sp. NGR234 (Fellay et al., 1995) to identify regions whose expression is enhanced by plant root exudates or specific flavonoids.

The use of this technique, coupled with the existence of a complete map of the pSym of Rbizobium etli (Girard et al., 1991), allows us to evaluate the extent of transcriptional activity under different conditions. In this work, we report quantitative maps of gene expression in the $\mathrm{pSym}$ in response to growth on several carbon and nitrogen sources, flavonoid induction and microaerobic conditions, and during symbiosis.

\section{METHODS}

Bacterial strains, plasmids and media. The bacterial strains and plasmids used are listed in Table 1. Rhizobium strains were grown at $30^{\circ} \mathrm{C}$ in PY rich medium (Noel et al., 1984) or in Y minimal medium with different carbon and nitrogen sources, each at a concentration of $10 \mathrm{mM}$ (Bravo \& Mora, 1988). Carbon sources were sodium succinate, glucose or glycerol; nitrogen sources were ammonium chloride, potassium nitrate, sodium glutamate or glutamine. Eschericbia coli strains were grown at $37^{\circ} \mathrm{C}$ in LB medium (Miller, 1972). Antibiotics were added at the following concentrations: chloramphenicol $(\mathrm{Cm})$, $25 \mu \mathrm{g} \mathrm{ml}^{-1}$ (E. coli) or $10 \mu \mathrm{g} \mathrm{m}^{-1}$ (R. etli); kanamycin (Km), $30 \mu \mathrm{g} \mathrm{ml}^{-1}$ (R. etli); nalidixic acid (Nal), $20 \mu \mathrm{g} \mathrm{m} \mathrm{m}^{-1}$ (R. etli); spectinomycin (Sp), $50 \mu \mathrm{g} \mathrm{ml}^{-1}$ (E. coli or R. etli); tetracycline, $10 \mu \mathrm{g} \mathrm{ml}^{-1}$ (E. coli) or $5 \mu \mathrm{g} \mathrm{ml^{-1 }}$ (R. etli).

Genetic manipulations. Plasmid pGC479 is a pSUP202 derivative (Simon et al., 1983) that carries a 2170 bp HindIII fragment containing the nif $A$ gene of $R$. etli CFN42 (GenBank accession no. U31630). As a first step in the generation of a mutation in the nif $A$ gene from R. etli, a 394 bp fragment from nif $A$ (position 1165-1559) was excised from pGC479 by digestion with EcoRI. A $2 \cdot 0 \mathrm{~kb} \Omega \mathrm{Sp} / \mathrm{Sm}$ (Prentki \& Krisch, 1984) cassette was then ligated in its place, thus generating pGC480. Double recombinants carrying the nif $A_{\Delta}:: \Omega S \mathrm{p} / \mathrm{Sm}$ allele in R. etli were obtained by standard genetic procedures (Martínez et al., 1990). This replacement was confirmed by Southern hybridization (Ausubel et al., 1987) using the nif $A$ gene of R. etli as a probe, and also by plant tests in which this strain was completely ineffective for nitrogen fixation. The resulting nif $A$ mutant strain was designated CFNX247.

Construction of a strain lacking the pSym but harbouring the wild-type nif $A$ gene on a replicating plasmid was done as follows. The strain CFNX248 was constructed by a triparental mating using $\mathrm{R}$. etli CFNX89 as the recipient and HB101/ pNC206 (Table 1) as cointegrative plasmid for HB101/pGC479; cointegration between these plasmids occurred through recombination among ampicillin resistance genes shared by these plasmids. The derivatives were selected as $\mathrm{Nal}^{\mathrm{r}} \mathrm{Cm}^{\mathrm{r}} \mathrm{Km}^{\mathrm{r}}$ transconjugants. They were analysed by Southern blot hybridization and plasmid profiles (Eckhardt, 1978).

Growth conditions. Cultures were grown to mid-exponential phase in PY medium. Cells were collected by centrifugation (at $6000 \mathrm{~g}$ in a Sorvall SS34 rotor), washed with sterile minimal medium and concentrated 100 -fold. Fresh Y minimal medium containing the desired carbon and nitrogen sources was inoculated with these suspensions at an initial $\mathrm{OD}_{540}$ of $0 \cdot 05$. For growth under microaerobic conditions, sodium succinate and ammonium chloride were used as carbon and nitrogen sources, respectively. Twenty milliliters of these cultures were incubated either in $150 \mathrm{ml}$ bottles closed with a cotton stopper (aerobic conditions), or in $150 \mathrm{ml}$ bottles closed with an airtight stopper and previously flushed with several volumes of an oxygen/argon $(1: 99, \mathrm{v} / \mathrm{v})$ mixture (microaerobic conditions). Both types of cultures were grown with shaking (200 r.p.m.) for $8 \mathrm{~h}$ at $30^{\circ} \mathrm{C}$. Cells were then collected by centrifugation $(6000 \mathrm{~g})$ at $4{ }^{\circ} \mathrm{C}$ and pellets were stored at $-70^{\circ} \mathrm{C}$ until RNA isolation.

Genistein induction. Cultures grown for $1 \mathrm{~d}$ on $\mathrm{PY}$ agar plates were used to inoculate a minimal medium with the following composition: sucrose, $5 \mathrm{mM} ; \mathrm{KNO}_{3}, 1 \mathrm{mM} ; \mathrm{K}_{2} \mathrm{HPO}_{4}, 1 \mathrm{mM}$; $\mathrm{KH}_{2} \mathrm{PO}_{4}, 7 \mathrm{mM} ; \mathrm{MgSO}_{4}, 1 \mathrm{mM} ; \mathrm{NaCl}, 2 \mathrm{mM} ; \mathrm{CaCl}_{2}, 0.1 \mathrm{mM}$; biotin, $0.4 \mathrm{mM}$; ferric citrate, $0.2 \mathrm{mM} ; \mathrm{H}_{3} \mathrm{BO}_{3}, 46 \mu \mathrm{M} ; \mathrm{MnSO}_{4}$, $9 \mu \mathrm{M} ; \mathrm{ZnSO}_{4}, 0.076 \mu \mathrm{M} ; \mathrm{CuSO}_{4}, 0.3 \mu \mathrm{M} ; \mathrm{Na}_{2} \mathrm{MoO}_{4}, 0.4 \mu \mathrm{M}$. Cultures were inoculated at an initial $\mathrm{OD}_{600}$ of 0.1 and grown with shaking (200 r.p.m.) for $4 \mathrm{~h}$ at $30^{\circ} \mathrm{C}$. Genistein was then added at a final concentration of $1.2 \mu \mathrm{M}$, with further incubation for $1,4,8$ or $24 \mathrm{~h}$. Control cultures were treated similarly, but without genistein addition. At the appropriate times, samples were withdrawn and cells were collected by centrifugation $(6000 \mathrm{~g})$ at $4{ }^{\circ} \mathrm{C}$ and pellets were stored at $-70^{\circ} \mathrm{C}$ until RNA isolation. To verify the production of nodulation factors, parallel $1 \mathrm{ml}$ cultures were labelled $3 \mathrm{~h}$ after genistein addition with $0 \cdot 2 \mu \mathrm{Ci}(7 \cdot 4 \mathrm{kBq}) \mathrm{D}-\left[1-{ }^{14} \mathrm{C}\right]$ glucosamine, and grown for $12 \mathrm{~h}$. Culture supernatants were analysed by thin-layer chromatography as described previously (Mendoza et al., 1995).

Plant growth. Surface-sterilized Phaseolus vulgaris cv. Negro Jamapa seeds (kindly provided by PRONASE) were germinated under sterile conditions in trays containing vermiculite. After $3 \mathrm{~d}$ at $30^{\circ} \mathrm{C}$, the seedlings were transferred to 11 plastic pots filled with sterile vermiculite and inoculated with $1 \mathrm{ml}$ of an overnight culture (in PY medium) of R, etli CFN42. Plants were grown in a greenhouse and watered periodically with a $\mathrm{N}$-free nutrient solution (Vincent, 1970) as previously described (Romero et al., 1988). After $25 \mathrm{~d}$, nodules were picked out from the roots, washed briefly with diethyl-pyrocarbonate-treated water and surface-sterilized. They were then immediately frozen in a dry-ice-ethanol bath and stored at $-20^{\circ} \mathrm{C}$ until further use.

Bacteroid purification. Bacteroids were purified from root nodules ( $3 \mathrm{~g}$, fresh wt), obtained as described above, by centrifugation through self-generated Percoll gradients (Reibach et al., 1981). Purified bacteroids were utilized immediately for RNA purification.

RNA purification. Total RNA extraction from purified bacteroids and from cells grown under aerobic or microaerobic conditions was done by the acid phenol procedure, employing a commercial kit (RNaid kit, BIO101). RNA was quantified by absorbance measurements and electrophoresed under de- 
Table 1. Bacterial strains and plasmids used in this study

\begin{tabular}{|c|c|c|}
\hline Strain or plasmid & Relevant properties & Source or reference \\
\hline \multicolumn{3}{|l|}{ Strain } \\
\hline \multicolumn{3}{|l|}{ Rbizobium etli } \\
\hline CFN42 & Wild-type strain & Quinto et al. (1985) \\
\hline CFNX89 & CFN42 derivative lacking the pSym & Brom et al. (1992) \\
\hline CFNX247 & $\begin{array}{l}\text { CFN42 derivative carrying the } \\
\text { nif } A_{\Delta}:: \Omega \mathrm{Sp} / \mathrm{Sm} \text { allele }\end{array}$ & This work \\
\hline CFNX248 & $\begin{array}{l}\text { CFNX89 derivative carrying a cointegrate } \\
\text { plasmid pNC206/pGC479 }\left(\text { nif } A^{+}\right)\end{array}$ & This work \\
\hline \multicolumn{3}{|l|}{ Eschericbia coli } \\
\hline HB101 & Host for recombinant plasmids & $\begin{array}{l}\text { Boyer \& Roulland- } \\
\text { Dussoix (1969) }\end{array}$ \\
\hline \multicolumn{3}{|l|}{ Plasmids } \\
\hline pSUP202 & Suicide vector, $A p^{r} \mathrm{Cm}^{r} \mathrm{Tc}^{r}$ & Simon et al. (1983) \\
\hline $\mathrm{pNC} 206$ & $\begin{array}{l}\text { A deleted RP4 derivative, } A p^{r} \mathrm{Km}^{\mathrm{r}} \text {, self- } \\
\text { replicating in Rbizobium spp. }\end{array}$ & $\begin{array}{l}\text { A. Pühler, Universität } \\
\text { Bielefeld, Germany. }\end{array}$ \\
\hline pRK2013 & Conjugation helper & $\begin{array}{l}\text { Figurski \& Helinski } \\
(1979)\end{array}$ \\
\hline pGC479 & $\begin{array}{l}\text { A pSUP202 derivative carrying the wild- } \\
\text { type nif } A \text { gene }\end{array}$ & This work \\
\hline pGC480 & $\begin{array}{l}\text { A pGC } 479 \text { derivative carrying the } \\
\text { nif } A_{\Delta}:: \Omega \mathrm{Sp} / \mathrm{Sm} \text { allele }\end{array}$ & This work \\
\hline cGD collection & $\begin{array}{l}\text { Ordered cosmid collection from the pSym } \\
\text { of } \mathrm{R} \text {. etli CFN42 }\end{array}$ & Girard et al. (1991) \\
\hline
\end{tabular}

naturing conditions in agarose-formaldehyde gels (Ausubel et al., 1987).

Synthesis of total ${ }^{32} \mathrm{P}$-labelled single-stranded complementary DNA (32P-sscDNA). This was done by the random hexamer priming method (Sambrook et al., 1989). The reaction mixture contained $1 \mu \mathrm{g}$ total RNA; $0.3 \mu \mathrm{g}$ of a random hexanucleotide (Amersham); 0.5 mM dGTP, dATP and dTTP; $5 \mu \mathrm{M}$ dCTP; $80 \mu \mathrm{Ci}\left[\alpha^{3}{ }^{32} \mathrm{P}\right] \mathrm{dCTP}\left[6000 \mathrm{Ci} \mathrm{mmol}^{-1}\right.$ (222 TBq $\left.\mathrm{mmol}^{-1}\right)$; 20 units placental ribonuclease inhibitor (Gibco BRL); 5 mM DTT; 400 units M-MLV Reverse Transcriptase (Gibco BRL) in the presence of first strand buffer (Gibco BRL); in a total volume of $30 \mu \mathrm{l}$. The reaction mixture was incubated for $90 \mathrm{~min}$ at $37^{\circ} \mathrm{C}$. To hydrolyse the RNA templates, EDTA, SDS and $\mathrm{NaOH}$ were added at final concentrations of $50 \mathrm{mM}$, $0.4 \%$ and $0.36 \mathrm{M}$, respectively, and the mixture was incubated for $30 \mathrm{~min}$ at $68^{\circ} \mathrm{C}$. For neutralization, Tris buffer $(\mathrm{pH} \mathrm{7.4)}$ and $\mathrm{HCl}$ were then added at final concentrations of $0.33 \mathrm{M}$ and $0 \cdot 2 \mathrm{M}$, respectively. Samples were precipitated with ethanol in the presence of tRNA as carrier, resuspended in $0.1 \mathrm{M} \mathrm{NaOH}$ and used as hybridization probes (A. Garay, personal communication).

Hybridization conditions and data analysis. Equal amounts of the cosmids that cover the whole pSym of $\mathrm{R}$. etli CFN42 (quantified spectrophotometrically) were digested with Bam HI, electrophoresed in $1 \%(\mathrm{w} / \mathrm{v})$ agarose gels and transferred to Nylon membranes (Hybond-N+, Amersham) (Ausubel et al., 1987). DNA blots were hybridized in a solution containing $50 \%$ (v/v) formamide as described previously (Girard et al., 1991). Hybridization signals were integrated by scanning the autoradiographs with a GS300 scanning densitometer using the GS$365 \mathrm{~W}$ data system (Hoefer Scientific Instruments), taking care that measurements were within the linear range of the film.

\section{RESULTS}

\section{Experimental design}

In order to study the global transcriptional patterns of the pSym of R. etli CFN42 under different conditions, we took advantage of the physical map of this plasmid, previously established in our laboratory. This map was assembled from an ordered cosmid collection, comprising $85 \mathrm{BamHI}$ fragments, which are numbered consecutively on the circular map from an arbitrary start in the nifHDK region a (Girard et al., 1991). Hybridization with probes representing the total RNA population from different conditions against the whole cosmid set allows us to determine the extent and localization of transcriptional activity on the pSym. To this end, total RNA was isolated from cultures grown under different conditions and from bacteroids (see Methods). These RNAs were used as templates for the synthesis of ${ }^{32} \mathrm{P}$-sscDNAs, which were then employed as probes in hybridization experiments against the whole cosmid collection. In these experiments, signal intensity in the autoradiographs was taken as a measure of the relative abundance of the mRNA corresponding to a certain region, i.e. its degree of expression. Pairwise comparison between treatments allowed the determination of induction or repression ratios, which are defined as the quotient between the conditions to be compared. To make valid comparisons between the different data sets, densitometric scannings were normalized according to the total radioactivity in the probes, exposure time and amount of cosmid DNA loaded in the 
(a)

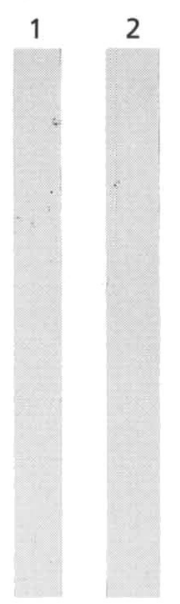

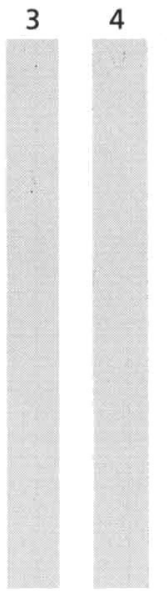

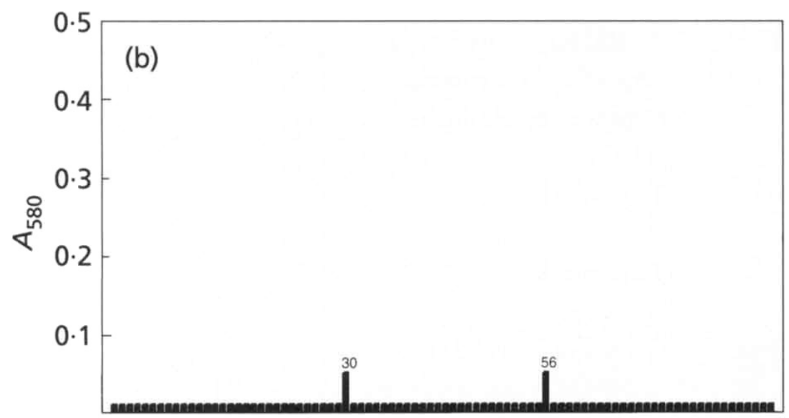

BamHI fragment

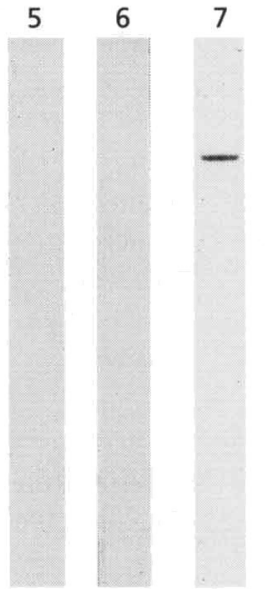

(c)
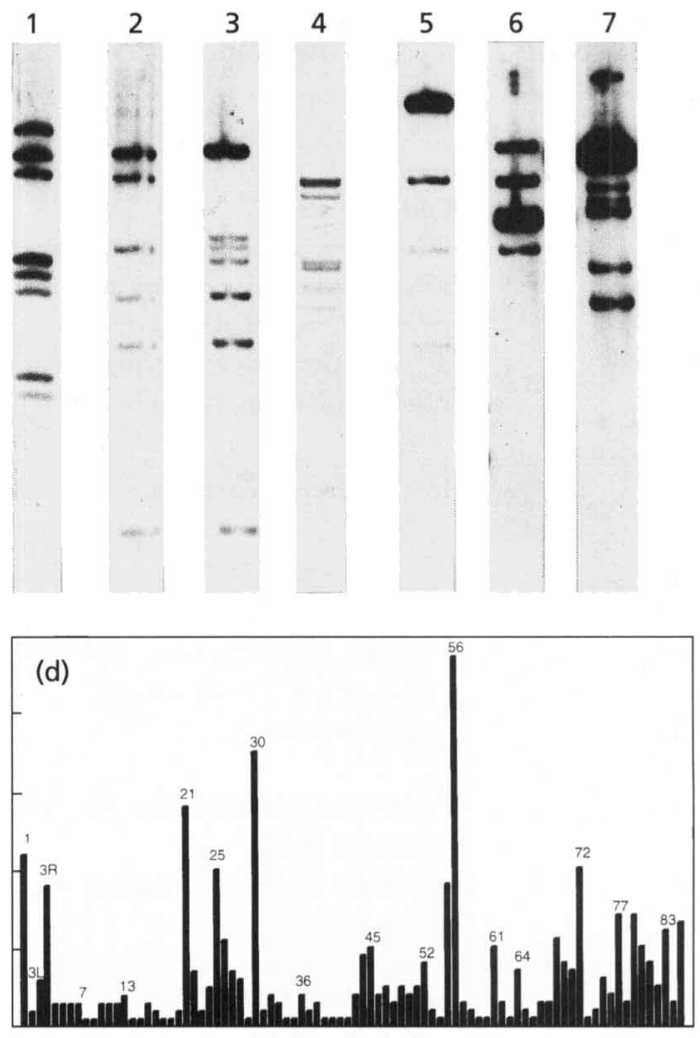

BamHI fragment

Fig. 1. Detection of transcriptional patterns of the R. et/i pSym and their quantification. The patterns were obtained using as probes ${ }^{32}$ P-ssCDNAs from strain CFN42 grown in succinate-ammonium medium under aerobic ( $a$, b) or microaerobic $(c, d)$ conditions. $(a, c)$ Southern blot hybridizations of a set of cosmid clones from the pSym digested with BamHI. Lanes: 1, cGD7 (bands 80-2); 2, cGD102 (bands 1-7); 3, cGD101 (bands 3-12); 4, cGD28 (bands 9-21); 5, cGD15 (bands 20-24); 6, cGD35 (bands 21-26); 7, cGD45 (bands 24-31). (b, d) Results of densitometric integration of hybridization signals for the whole pSym. Bar numbers indicate the position of specific fragments on the map (Fig. 3a).

gels, as described in Methods. An example of this type of analysis is shown in Fig. 1.

This experimental design assumes that the signals observed are due to transcription of sequences in the pSym, which are specifically detected through high-stringency hybridization against our cosmid collection. Although this is a reasonable assumption, reiteration of some potentially transcribable regions occurs in other replicons in the cell (Girard et al., 1991). To exclude the possibility that detectable transcription originated from these reiterated regions, RNA was isolated from microaerobic cultures of strain CFNX.248. 'This strain lacks the pSym but carries an active nif $A$ gene on an autonomous, selfreplicating plasmid (see Methods). Microaerobic conditions in the wild-type strain provoked a widespread, nif $A$ dependent transcription in the pSym (see below). If detectable transcription originated from reiterated DNA, hybridization signals should be observed with a probe made using microaerobically-grown CFNX248. No hybridization signals were observed with ${ }^{32} \mathrm{P}$-sscDNA synthesized from this strain (data not shown). Thus, the transcriptional activity detected in our experiments originated from sequences on the pSym, and not from reiterations located elsewhere in the genome.

\section{Carbon and nitrogen sources modulate transcriptional activity in the pSym}

To evaluate the role of nutritional stimuli on pSym expression under aerobic conditions, transcript levels were analysed after growth in a variety of carbon and nitrogen sources. As shown in Fig. 1(a), growth of the wild-type strain in a $\mathrm{C}$ - and $\mathrm{N}$-rich medium (succinate plus ammonium) was very restrictive in terms of transcriptional activity. Only two regions (bands 30 and 56) were expressed at a detectable level, while the rest of the plasmid was not expressed. This profile was taken as the baseline expression pattern of the pSym. To discern between effects caused by different $\mathrm{N}$ or $\mathrm{C}$ sources, media containing succinate and glutamine, glutamate or $\mathrm{KNO}_{3}$ were used. For comparison of the effects between the different treatments, expression values obtained in any given treatment were divided by the corresponding values 
obtained under the baseline condition (succinate plus ammonium), thus deriving induction ratios. Growth on glutamine (Fig. 2a) led to higher induction than ammonium. In contrast, growth on a moderate (glutamate, Fig. 2b) or poor $\left(\mathrm{KNO}_{3}\right.$, Fig. 2c) nitrogen source provoked a gradual increase in induction ratios. Growth on $\mathrm{KNO}_{3}$ led to the activation of 16 regions, with induction ratios ranging from $2 \cdot 5$ to $7 \cdot 3$. Growth on medium containing ammonium and glucose (Fig. $2 \mathrm{~d}$ ) or glycerol (Fig. 2e) as alternative carbon sources promoted higher transcriptional activity than succinate, leading to the activation of 10 regions at induction ratios ranging from $2 \cdot 5$ to $9 \cdot 6$. Thus, transcriptional activity in the $\mathrm{pSym}$ is modified by the type of nitrogen and carbon sources employed.

\section{Temporal order of pSym expression in response to flavonoid induction}

Flavonoid compounds are components of root exudates which are important mediators in the chemical communication between bacteria and leguminous plants. Flavonoids are responsible for the induction of genes involved in the nodulation process, but it has been suggested that they are also involved in other steps of the symbiotic interaction, such as competitivity (Bhagwat \& Keister, 1992; Sadowsky et al., 1988). To identify the extent and location of pSym regions induced by the isoflavone genistein, cultures were grown in sucrose$\mathrm{KNO}_{3}$ minimal medium (see Methods) and expression values were obtained at different times after genistein addition. As a control, expression values were obtained from parallel cultures treated similarly, but without added genistein. Induction or repression ratios are expressed as the quotient of the values obtained in the presence vs the absence of genistein. Four different regions, differing in temporal order after induction, could be recognized (Fig. $2 \mathrm{f}-\mathrm{i}$ ). Members of region I, spanning bands 1-11, showed an early pattern of induction. Expression was detectable $1 \mathrm{~h}$ after genistein addition, achieving maximal levels $24 \mathrm{~h}$ after the onset of the induction period. In contrast, regions II-IV (bands 22-26; 43-51 and 80-85, respectively) were clearly induced only after $24 \mathrm{~h}$. Under our conditions, production of Nod factors was detectable at $15 \mathrm{~h}$ after induction (data not shown). All the nodulation genes so far identified in $R$. etli are contained in region I and in part of region IV (see Fig. $3 \mathrm{a}$ and Discussion); however, regions II and III mark the location of new, isoflavone-induced sectors that might be involved in nodulation or other flavonoid-controlled processes.

\section{Transcriptional activity of the pSym is regulated by oxygen concentration}

Oxygen limitation is an important metabolic effector of expression of many genes involved in nitrogen fixation. The effect of this environmental variable was explored by growing the wild-type strain in a medium containing succinate and ammonium, under both aerobic and microaerobic conditions (see Methods). Extensive expression of genes borne by the pSym was observed under microaerobic conditions: 67 out of $85 \mathrm{BamHI}$ bands were expressed (Fig. 1b). This is more clearly seen when induction ratios (microaerobic vs aerobic levels) are considered. As shown in Fig. 2j, oxygen limitation provokes widespread induction of expression in the pSym, with ratios ranging from 2 to 28 . Transcription of most of the nif and fix genes in Rhizobium is dependent on the nif $A$ gene product, under both microaerobic and symbiotic conditions (Fischer, 1994). A comparison of the induction ratios achieved under microaerobic conditions in the wild-type strain (Fig. 2j) and in the nif $A$ mutant strain (Fig. 2k) allowed us to classify the different pSym regions according to their degree of dependency on the nif $A$ gene product. Thirty-seven fragments showed an absolute dependency for this gene, i.e. they were expressed in the wild-type strain but not in the nif $A$ mutant strain. Twenty-nine fragments showed lower induction ratios in the nif $A$ mutant strain, suggesting a partial dependency for this transcriptional activator. The extent of this dependency varied widely, since the induction ratios ranged from $1 \cdot 2$ to values 10 -fold larger in the wild-type as compared to the mutant strain.

These results indicate that (i) oxygen limitation leads to a dramatic induction in the transcriptional activity of the pSym, and (ii) that the NifA transcriptional activator partially controls this response.

\section{General transcriptional activity of the pSym during symbiosis}

The transcription pattern of the pSym during symbiosis was only studied in the wild-type strain, due to the low recovery of bacteroids from nodules induced by the nif $A$ mutant. To this end, ${ }^{32} \mathrm{P}$-sscDNA was synthesized from total bacteroid RNA of the wild-type strain. This ${ }^{32} \mathrm{P}$ sscDNA was then used as a probe. Under symbiotic conditions, almost all the plasmid was actively transcribed. In fact, the absolute transcriptional levels during this stage were the highest among the conditions tested. As shown in Fig. 2(1), induction ratios during symbiosis vs aerobic conditions (succinate plus ammonium) may be as high as 46-fold. Two contiguous regions in the $\mathrm{pSym}$, spanning fragments $80-85$ and $1-29$, contain most of the fragments with a high induction during symbiosis (Fig. $2 \mathrm{l})$; many of the symbiotic genes detected in this organism are located here (see Discussion).

The induction ratios observed during symbiosis (Fig. 2l) are qualitatively similar to the ones seen during microaerobiosis (Fig. 2j). To further explore the observed similarity in transcription patterns, data were plotted as the quotient of the values during symbiosis vs microaerobiosis. As shown in Fig. 2(m), 41 fragments of the pSym were induced during symbiosis at levels well above the ones observed under low oxygen conditions. Fourteen fragments were expressed at the same level in both conditions; fifteen fragments that showed expression under low oxygen tensions were repressed in bacteroids. 

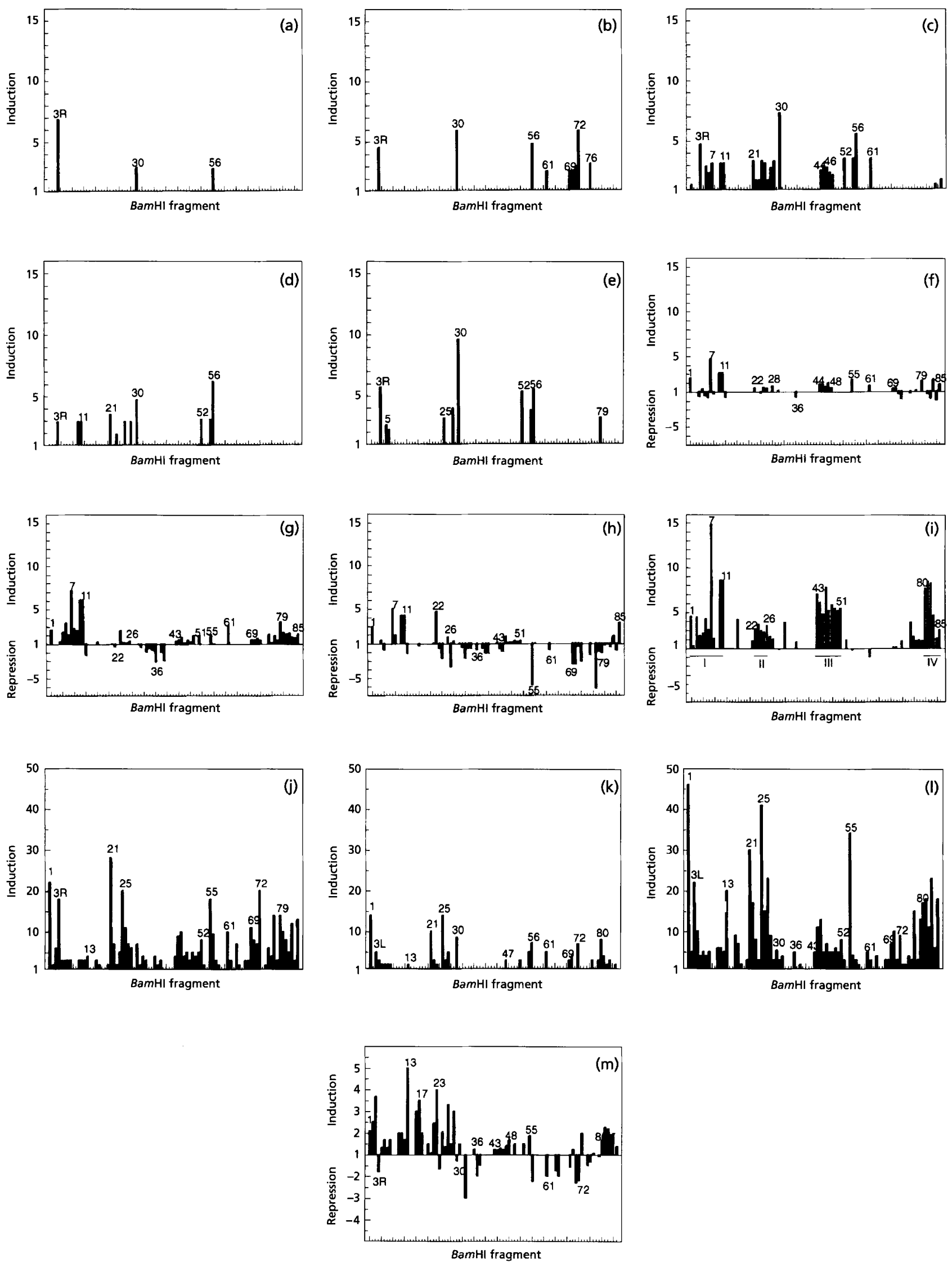

Fig. 2. For legend see facing page. 
(a)

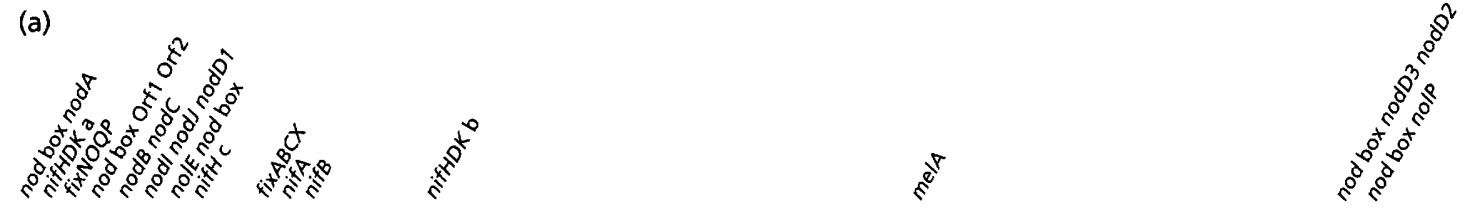

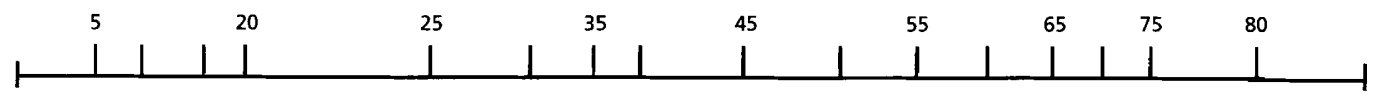

(b)

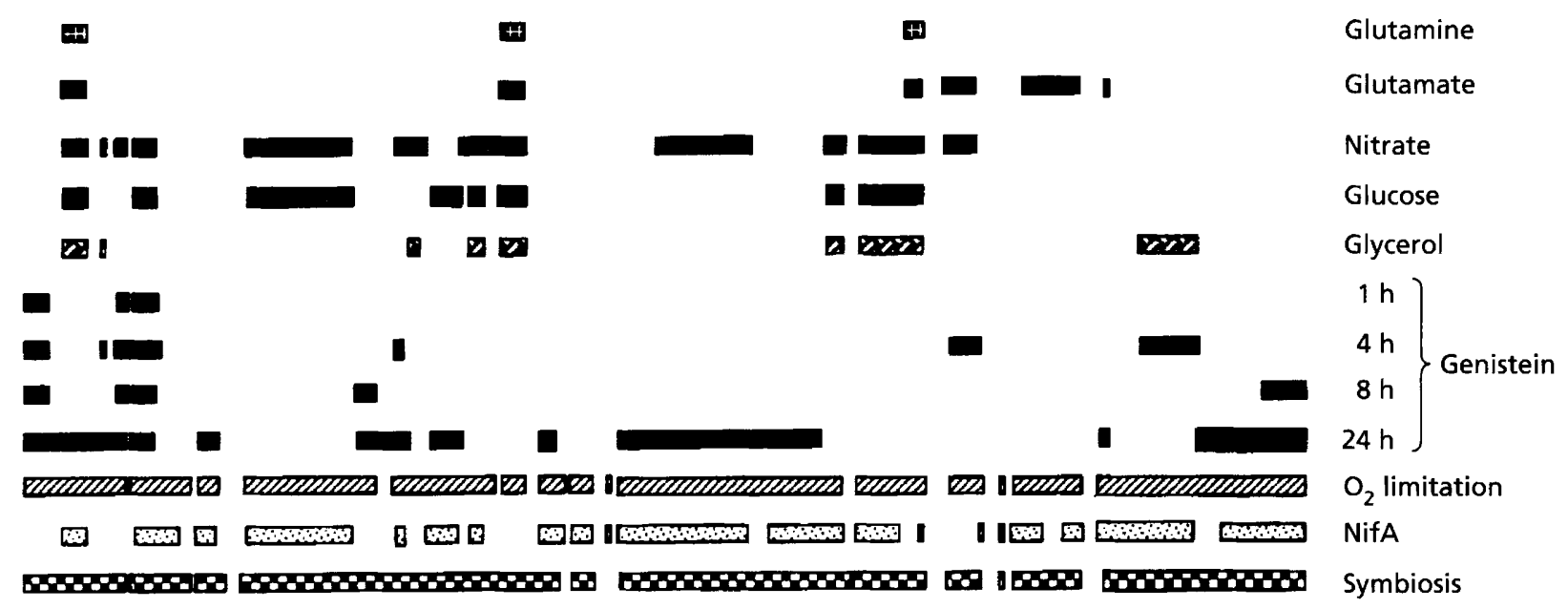

Fig. 3. Transcriptional activity in the $R$. et/i pSym. (a) Linear BamHI map of the $390 \mathrm{~kb}$ pSym of $R$. et/i CFN42, indicating the location of specific symbiotic genes. The location of these genes was compiled from data given by Girard et al. (1991); Vázquez et al. (1991, 1993); and our own unpublished results. Exact locations for specific genes are: nod box, nodA and nifHDK a (band 1); fixNO (band 3); fixQP (band 4); nod box, ORF 1-2 and nodB (band 7); nodC (band 8); nodIJ (band 10); nodD1 (bands 10-11); nolE (band 11); nifH c (band 13); fixABCX, nifA and nifB (band 21); nifHDK b (band 25); melA (bands 55-56); nod box, nodD3, nodD2, nod box and nolP (band 85). Numbers indicate the corresponding BamHI fragments. (b) Extent of transcriptional activity under each environmental condition tested. In this figure, only bands that showed an induction ratio over 2.5 were considered.

\section{DISCUSSION}

How many regions in a symbiotic plasmid are actively expressed during symbiosis? How much of this information is regulated by other physiological stimuli? In this paper we approached these questions through the determination of the global transcription patterns in the pSym. Our analyses were greatly aided by a sensitive technique that allows the quantitative detection of the transcriptional activity in specific genomic regions (Chuang et al., 1993). The validity of this approach is supported by the fact that the transcriptional activity detected originates from the pSym (see Results).

Two limitations need to be considered to analyse these experiments. First, it is not generally possible to equate transcriptional activity of a region with the activity of single genes due to the possibility that a region may contain several transcriptional units. A second limitation is that if transcripts are generated from a multigene family located exclusively in the same replicon (such as the nif $H D K$ reiterations in the $\mathrm{pSym}$ ), the total transcriptional activity detected may be due to any or all the members of the family. Nevertheless, this approach is valuable for the identification and localization of regions which respond to defined environmental stimuli.

Fig. 3 shows a correlation between the quantitative maps of transcriptional activity obtained in this work and the

Fig. 2. Comparison of the levels of induction in the $R$. et/i pSym under different conditions. For each fragment, induction ratios were calculated as a quotient of absolute transcript levels (Fig. 1) between the conditions to be compared. For repression, the reciprocal of the induction ratios were plotted. For these comparisons, a value corresponding to the minimal detection level $\left(A_{580} 0.01\right)$ was assigned to unexpressed regions. (a-e) Induction by glutamine (a), glutamate (b), nitrate (c), glucose (d) and glycerol (e) compared with the wild-type strain grown in succinate-ammonium medium under aerobic conditions. ( $\mathrm{f}-\mathrm{i})$ Induction by genistein at $1 \mathrm{~h}(\mathrm{f}), 4 \mathrm{~h}(\mathrm{~g}), 8 \mathrm{~h}(\mathrm{~h})$ and $24 \mathrm{~h}$ (i) after addition compared with the corresponding control without genistein addition. $(j, k)$ Microaerobic induction in the wild-type strain (j) and in the nifA mutant strain $(k)$ compared with the wild-type strain grown under aerobic conditions. $(I, m)$ Symbiotic induction in the wild-type strain compared to the wild-type strain grown under aerobic (I) or microaerobic $(\mathrm{m})$ conditions. Bar numbers indicate the position of specific regions on the map (Fig $3 a$ ). 
location of specific genes on the pSym. It is noteworthy that physiological signals, such as the type of the carbon and nitrogen sources, exert significant control on the transcriptional activity of the pSym (Fig. 3b). In general, poorly utilized carbon or nitrogen sources allow a greater expression than rich ones. The expressed regions appear to be dispensable, since curing of the pSym does not affect growth rates under these conditions. Ex planta expression of some symbiotic genes in other Rbizobium species, such as nodD3 (Dusha \& Kondorosi, 1993), nifHDK and fix $A B C X$ (Szeto et al., 1987), is affected by the nitrogen source. In fact, it has been proposed that nitrogen status may control nodulation by $R$. etli via the $n \operatorname{tr} C$ gene product (Mendoza et al., 1995). Although the expression of some fragments under $\mathrm{C}$ - or $\mathrm{N}$-limited conditions might be explained by correspondence with known symbiotic genes, many of these fragments map in zones of the pSym lacking identifiable nod or fix genes. The functional status of these fragments is still uncertain, but they represent $\mathrm{N}$ - and $\mathrm{C}$-controlled regions that might be relevant for either saprophytic or symbiotic life-styles.

Four different regions were actively transcribed after induction with the isoflavone genistein. One of these (region I, Fig. 2i) contains most of the nodulation genes identified in R. etli (Fig. 3a). Complementation of a pSymcured strain with a cosmid clone containing region I leads to nodule formation (Cevallos et al., 1989); thus, this region is sufficient for nodulation. Region I shows an early pattern of expression, detectable $1 \mathrm{~h}$ after induction and achieves maximal levels after $24 \mathrm{~h}$. These data are in agreement with experiments employing transcriptional fusions with members of region $\mathrm{I}$, such as $\operatorname{nod} A$ and $\operatorname{nod} B C$, where high-level expression was observed after $24 \mathrm{~h}$ (Vázquez et al., 1991). All the new regions identified (regions II-IV, Fig. 2i) show a late pattern of inducibility, suggesting that these regions might be important in other flavonoid-influenced processes, such as efficiency of nodulation (Schultze et al., 1994), competitivity (Bhagwat \& Keister, 1992; Sadowsky et al., 1988), chemotaxis (Aguilar et al., 1988) or resistance to plant phytoalexins (Parniske et al., 1991).

A similar approach was recently employed with the pSym of Rhizobium sp. NGR234 (Fellay et al., 1995). Although the spatial order of equivalent zones is different from the pSym of CFN42, four flavonoid-inducible regions were also observed. Three of these were induced only late after flavonoid addition. Contrasting with our data, a locus similar to our region I (containing nod $A B C$ and other host-specificity genes) was expressed only shortly after flavonoid induction. This region becomes transcriptionally silent late after induction. Thus, both the topological arrangement and the temporal order of expression of equivalent zones may vary depending on the bacterial host.

It is commonly thought that the pattern of expression of nitrogen fixation genes under microaerobic conditions resembles the pattern observed during endosymbiotic stages. In fact, it has been recently proposed that oxygen limitation is a key determinant of the symbiotic pattern of nitrogen fixation gene expression in alfalfa nodules (Soupène et al., 1995). Our results show that oxygen concentration is one of the main effectors for induction of transcriptional activity in the pSym. Contrasting with the low expression of the pSym under most aerobic conditions, microaerobic status leads to a dramatic increase in the expression level for most of the fragments (Fig. 3b). Some of the induced fragments correspond to sectors that contain different nif and fix genes (for instance, both fragments 1 and 25 contain nifHDK operons, fragment 21 contains $f i x A B C$ and nif $A$ genes, Fig. 3a). However, functions encoded in many of the induced fragments are still unknown.

It is important to note that this microaerobic induction is dependent, either partially or totally, on the presence of an active nif $A$ gene (Fig $2 \mathrm{k}$ ). This dependency suggests that many induced fragments might have a role, either essential or ancillary, during the symbiotic process. Nevertheless, a detectable fraction of transcriptional activity in this condition is independent of nif $A$. It is possible that the remaining activity might be dependent on other oxygensensitive regulators, such as fixK (Fischer, 1994).

Symbiotic conditions gave the highest induction in the pSym. Our results show that most of the plasmid regions are expressed during symbiosis (Fig. 3b). Two contiguous regions account for most of the highly expressed fragments in this condition. Although some symbiotic genes, such as nifHDK, fix $A B C X$ and nif $A$, have been located in these fragments, the function of the others (Fig. $3 \mathrm{a}$ ) is largely unknown.

Considering the level of expression of these regions, it is plausible to think that they may be particularly relevant for symbiosis. In support of this, deletions that remove a sector comprising fragments $1-25$ lead to an inability to nodulate (Romero et al., 1991). In contrast, deletions that affect fragments $30-81$ are still able to nodulate and to fix nitrogen (unpublished data). The only other highly expressed region in the pSym is fragment 55, which apparently contains the $\operatorname{mel} A$ gene (unpublished data); this gene is expressed during both microaerobic and symbiotic stages (Hawkins \& Johnston, 1988).

Although our data are consistent with the role of oxygen as one of the main effectors of symbiotic expression, some discrepancies still remain. Our data for the symbiotic induction pattern resemble, but are not identical to, the microaerobic induction pattern. A comparison of both conditions (Fig. $2 \mathrm{~m}$ ), revealed that induction ratios were the same (i.e. close to one) for only fourteen expressed fragments. The rest of the fragments were either more induced or even repressed during symbiosis.

Microaerobic cultures similar to the ones we employed are commonly used to evaluate the level of expression of known symbiotic genes in vitro. Our comparisons are useful to evaluate the agreement between these conditions. Although there is a good qualitative agreement, there are important differences. It is now well established that the $\mathrm{O}_{2}$ concentration in the infected nodule tissue is about $50 \mathrm{nM}$ (Kuzma et al., 1993). Although the actual 
concentration of dissolved oxygen was not determined in our microaerobic cultures, calculations based on the published Ostwald coefficients for oxygen suggest that it was approximately $12 \mu \mathrm{M}$. The simplest explanation for the observed differences between the microaerobic and symbiotic induction patterns is that they are solely due to differences in oxygen concent ration. Another explanation is that there are other controls, superimposed on the one exerted by oxygen concentration, which act to determine the level of expression during symbiosis. Resolution of these alternatives must wait for quantitative determinations of expression levels under nanomolar oxygen concentrations.

Previous attempts to evaluate the global transcriptional activity of a pSym were restricted to some defined pSym sectors (David et al., 1987) or to isolated highly expressed regions from genome banks (Scott-Craig et al., 1991). However, a recent report from Fellay et al. (1995) evaluated the transcriptional activity of the whole pSym of Rhizobium sp. NGR234 under flavonoid or root exudate induction, employing an approach similar to the one described in this paper. Our data extend the usefulness of this approach, providing quantitative information on transcriptional activity on a different $\mathrm{pSym}$ under a variety of environmental conditions.

An additional application of this approach is in the evaluation of the effect of mutations in global transcriptional regulators, such as nif $A$. This type of analysis allows a rapid evaluation of the number and position of regions controlled by a complex regulatory circuit, either in a positive or a negative mode. We believe that the resolutive power achieved through a quantitative global approach will make it extremely useful for the analysis of complex genomes.

\section{ACKNOWLEDGEMENTS}

We are indebted to Susana Brom, Patrice Dion and Jaime Martínez-Salazar for critical reviewing of the manuscript; to Adriana Garay (Instituto de Biotecnología, UNAM) for help with cDNA synthesis; and to Sergio Caro, Laura Cervantes and María de la Paz Salas for skilful technical assistance.

\section{REFERENCES}

Aguilar, J. M. M., Ashby, A. M., Richards, A. J. M., Loake, G. A., Watson, M. D. \& Shaw, C. H. (1988). Chemotaxis of Rbizobium leguminosarum biovar phaseoli towards flavonoid inducers of the symbiotic nodulation genes. J Gen Microbiol 134, 2741-2746.

Ausubel, F. M., Brent, R., Kingston, R. E., Moore, D. D., Seidman, J. G., Smith, J. A. \& Struhl, K. (1987). Current Protocols in Molecular Biology. New York: John Wiley.

Bhagwat, A. A. \& Keister, D. L. (1992). Identification and cloning of Bradyrbizobium japonicum genes expressed strain selectively in soil and rhizosphere. Appl Environ Microbiol 58, 1490-1495.

Boyer, H. W. \& Roulland-Dussoix, D. (1969). A complementation analysis of restriction and modification of DNA in Escherichia coli. $J$ Mol Biol 41, 459-472.

Bravo, A. \& Mora, J. (1988). Ammonium assimilation in Rbizobium phaseoli by the glutamine synthetase-glutamate synthase pathway. J Bacteriol 170, 980-984.
Brom, S., Garcla de los Santos, A., Stepkowski, T., Flores, M., Dávila, G., Romero, D. \& Palacios, R. (1992). Different plasmids of Rbizobium leguminosarum bv. phaseoli are required for optimal symbiotic performance. J Bacteriol 174, 5183-5189.

Carlson, R. W., Price, N. P. J. \& Stacey, G. (1994). The biosynthesis of rhizobial lipo-oligosaccharide nodulation signal molecules. Mol Plant-Microb Interact 7, 684-695.

Cevallos, M. A., Vázquez, M., Dávalos, A., Espín, G., Sepúlveda, J. \& Quinto, C. (1989). Characterization of Rbizobium phaseoli $\mathrm{Sym}$ plasmid regions involved in nodule morphogenesis and host-range specificity. Mol Microbiol 3, 879-889.

Chuang, S., Daniels, D. L. \& Blattner, F. R. (1993). Global regulation of gene expression in Escberichia coli. I Bacteriol 175, 2026-2036.

David, M., Domergue, O., Pognonec, P. \& Kahn, D. (1987). Transcription patterns of Rhizobium meliloti symbiotic plasmid $\mathrm{pSym}$ : identification of nif $A$-independent fix genes. J Bacteriol 169 , 2239-2244.

Dusha, I. \& Kondorosi, A. (1993). Genes at different regulatory levels are required for the ammonia control of nodulation in Rbizobium meliloti. Mol Gen Genet 240, 435-444.

Eckhardt, T. (1978). A rapid method for the identification of plasmid deoxyribonucleic acid in bacteria. Plasmid 1, 584-588.

Fellay, R., Perret, X., Viprey, V., Broughton, W. J. \& Brenner, S. (1995). Organization of host-inducible transcripts on the symbiotic plasmid of Rbizobium sp. NGR234. Mol Microbiol 16, 657-667.

Figurski, D. H. \& Helinski, D. R. (1979). Replication of an origincontaining derivative of plasmid RK2 dependent on a plasmid function provided in trans. Proc Natl Acad Sci US A 76, 1648-1652.

Fischer, H.-M. (1994). Genetic regulation of nitrogen fixation in Rhizobia. Microbiol Rev 58, 352-386.

Girard, M. L., Flores, M., Brom, S., Romero, D., Palacios, R. \& Dávila, G. (1991). Structural complexity of the symbiotic plasmid of Rbirobium leguminosarum bv. phaseoli. J Bacteriol 173, 2411-2419.

Hawkins, F. K. L. \& Johnston, A. W. B. (1988). Transcription of a Rhizobium leguminosarum biovar phaseoli gene needed for melanin synthesis is activated by nif $A$ of Rhizobium and Klebsiella pneumoniae. Mol Microbiol 2, 331-337.

Kuzma, M. M., Hunt, S. \& Layzell, D. B. (1993). Role of oxygen in the limitation and inhibition of nitrogenase activity and respiration rate in individual soybean nodules. Plant Pbysiol 101, $161-169$.

Martínez, E., Romero, D. \& Palacios, R. (1990). The Rbizobium gcnome. Crit Rev Plant Sci 9, 59 93.

Mendoza, A., Leija, A., Martínez-Romero, E., Hernández, G. \& Mora, J. (1995). The enhancement of ammonium assimilation in Rhizobium etli prevents nodulation of Phaseolus vulgaris. Mol PlantMicrobe Interact 8, 584-592.

Miller, J. H. (1972). Experiments in Molecular Genetics. Cold Spring Harbor, NY: Cold Spring Harbor Laboratory.

Noel, K. D., Sánchez, F., Fernández, L., Leemans, J. \& Cevallos, M. A. (1984). Rbizobium phaseoli symbiotic mutants with transposon Tn5 insertions. J Bacteriol 158, 148-155.

Parniske, M., Ahlborn, B. \& Werner, D. (1991). Isoflavonoidinducible resistance to the phytoalexin glyceollin in soybean rhizobia. J Bacteriol 173, 3432-3439.

Perret, X., Broughton, W. J. \& Brenner, S. (1991). Canonical ordered cosmid library of the symbiotic plasmid of Rhizobium species NGR234. Proc Natl Acad Sci US A 88, 1923-1927.

Prentki, P. \& Krisch, H. M. (1984). In vitro insertional mutagenesis with a selectable DNA fragment. Gene 29, 303-313.

Quinto, C., de la Vega, H., Flores, M., Leemans, J., Cevallos, M. A., 
Pardo, M. A., Azpiroz, R., Girard, M. L., Calva, E. \& Palacios, R. (1985). Nitrogenase reductase: a functional multigene family in Rhizobium phaseoli. Proc Natl Acad Sci US A 82, 1170-1174.

Reibach, P. H., Mask, P. L. \& Streeter, J. G. (1981). A rapid one-step method for the isolation of bacteroids from root nodules of soybean plants, utilizing self-generating Percoll gradients. Can J Microbiol 27, 491-495.

Romero, D., Singleton, P. W., Segovia, L., Morett, E., Bohlool, B. B., Palacios, R. \& Dávila, G. (1988). Effect of naturally occurring nif reiterations on symbiotic effectiveness in Rbizobium phaseoli. Appl Environ Microbiol 54, 848-850.

Romero, D., Brom, S., Martínez-Salazar, J., Girard, M. L., Palacios, R. \& Dávila, G. (1991). Amplification and deletion of a nod-nif region in the symbiotic plasmid of Rbizobium phaseoli. J Bacteriol 173, 2435-2441.

Sadowsky, M. J., Olson, E. R., Foster, V. E., Kosslak, R. M. \& Verma, D.P. S. (1988). Two host-inducible genes of Rbizobium fredii and characterization of the inducing compound. J Bacteriol 170, 171-178.

Sambrook, J., Fritsch, E. F. \& Maniatis, T. (1989). Molecular Cloning: a Laboratory Manual, 2nd edn. Cold Spring Harbor, NY: Cold Spring Harbor Laboratory.

Sanjuan, J., Luka, S. \& Stacey, G. (1993). Genetic maps of Rbizobium and Bradyrbizobium species. In Genetic Maps, pp. 2136-2145. Edited by S. O'Brien. Cold Spring Harbor, NY: Cold Spring Harbor Laboratory.

Schultze, M., Kondorosi, E., Ratet, P., Buiré, M. \& Kondorosi, A. (1994). Cell and molecular biology of Rhizobium-plant interactions. Int Rev Cytol 156, 1-75.

Scott-Craig, J. S., Guerinot, M. L. \& Chelm, B. K. (1991). Isolation of Bradyrbizobium japonicum DNA sequences that are transcribed at high levels in bacteroids. Mol Gen Genet 228, 356-360.

Simon, R., Priefer, U. \& Puhler, A. (1983). Vector plasmids for invitro manipulations of Gram-negative bacteria. In Molecular Genetics of the Bacteria-Plant Interaction, pp. 98-106. Edited by A. Pühler. Berlin: Springer-Verlag.

Soupène, E., Foussard, M., Boistard, P., Truchet, G. \& Batut, J. (1995). Oxygen as a key developmental regulator of Rbizobium meliloti $\mathrm{N}_{2}$-fixation gene expression within the alfalfa root nodule. Proc Natl Acad Sci US A 92, 3759-3763.

Szeto, W. W., Nixon, B. T., Ronson, C. W. \& Ausubel, F. M. (1987), Identification and characterization of the Rhizobium meliloti ntrC gene: R. meliloti has separate regulatory pathways for activation of nitrogen fixation genes in free-living and symbiotic cells. $J$ Bacteriol 169, 1423-1432.

Van Rhijn, P. \& Vanderleyden, J. (1995). The Rbizobium-plant symbiosis. Microbiol Rev 59, 124-142.

Vázquez, M., Dávalos, A., de las Peñas, A., Sánchez, F. \& Quinto, C. (1991). Novel organization of the common nodulation genes in Rbizobium leguminosarum bv. phaseoli strains. J Bacteriol 173, $1250-1258$

Vázquez, M., Santana, O. \& Quinto, C. (1993). The NodI and NodJ proteins from Rhizobium and Bradyrbizobium strains are similar to capsular polysaccharide secretion proteins from gramnegative bacteria. Mol Microbiol 8, 369-377.

Vincent, J. M. (1970). A Manual for the Practical Study of Root Nodule Bacteria. IBP Handbook no. 15. Oxford: Blackwell Scientific Publications.

Received 29 April 1996; revised 19 June 1996; accepted 24 June 1996. 